\title{
An Experimental Simulation of a Design Three-Port DC-DC Converter
}

\author{
Samir Al Sharif1, Ahmad Harb2 ${ }^{2}$ Haibing Hu3, Issa Batarseh ${ }^{3}$ \\ ${ }^{1}$ Electrical Engineering Department, Taibah University, Madinah, KSA \\ ${ }^{2}$ Energy Engineering Department, German Jordanian University, Amman, Jordan \\ ${ }^{3}$ Electrical Engineering and Computer Science Department, University of Central Florida, Orlando, USA \\ Email: aharb48@gmail.com
}

Received 1 August 2014; revised 23 August 2014; accepted 3 September 2014

Copyright (C) 2014 by authors and Scientific Research Publishing Inc.

This work is licensed under the Creative Commons Attribution International License (CC BY).

http://creativecommons.org/licenses/by/4.0/

(c) (i) Open Access

\section{Abstract}

Traditional DC-DC converter topologies interface two power terminals: a source and a load. The construction of diverse and flexible power management and distribution (PMAD) systems with such topologies is governed by a tight compromise between converter count, efficiency, and control complexity. The broader impact of the current research activity is the development of enhanced power converter systems suitable for a wide range of applications. Potential users of this technology include the designers of portable and stand-alone systems such as laptops, hand-held electronics, and communication repeater stations. High power topology options support the evolution of clean power technologies such as hybrid-electric vehicles (HEV's) and solar vehicles. DCDC converter is considered as an advanced environmental issue since it is a greenhouse emission eliminator. By utilizing the advancement of these renewable energy sources, we minimize the use of fossil fuel. Thus, we will have a cleaner and pollution free environment. In this paper, a threeport DC-DC converter is designed and discussed. The converter was built and tested at the energy research laboratory at Taibah University, Al Madinah, KSA.

\section{Keywords}

DC-DC Converter, Power Electronics

\section{Introduction}

The integrated power electronic converters are important for systems that are capable of harvesting power from solar sources, fuel cells and mechanical vibrations used in applications such as communication repeater stations, sensor networks, hybrid electric vehicles and laptops [1]-[10]. Moreover, multi-terminal interface is important 
since such systems require mass energy storage to compensate for the mismatch between the sourcing and loading power patterns over a regular operational cycle. For example, a solar system, consisting of a regulated load interfaced to a solar array, requires storage batteries for storing excess power and re-supplying it to the load when needed. Limited research activities on multi-terminal converter topologies have been reported in open literature, with very few commercially installed systems in industry. Interesting ideas for multi-sourced converters with multiple control variables have been introduced based on the flyback (buck-boost) converter topology.

An investigation of conventional system architectures, composed of two-terminal converters, emphasizes the significance of the advent of practical and flexible single-stage multi-terminal converters. Following on the battery-backed solar system example, the main candidate architectures are [11]-[17]:

1) Two stage interface: The solar array is interfaced to an intermediate battery-dominated bus allowing MPPT, as shown in Figure 1, with another converter stage interfaces that bus to the load. The main disadvantage of this scheme is that solar power goes through two loosely conversion stages, before reaching the load.

2) Independent charge and discharge: The battery bidirectional converter can be split into two unidirectional converters: a charger interfaced to the input bus, and a discharge converter interfaced to the load bus, as seen in Figure 2. This assures that power goes through one conversion stage when traveling between any two terminals, allowing for higher efficiency. The price paid is an additional converter, increasing the size, weight, cost, component count, and control complexity of the system.

We believe that due to the added complexity, together with increased losses, size, weight, and cost, as well as decreased reliability, has impeded wide-spread adoption of such architectures for many applications. The potentially profitable MPPT technology has been very difficult to justify in many applications given the cost and control complexity overhead. An integrated three-terminal converter that performs the functions of the three-converter structure using a single power stage can overcome these challenges, and is thus very attractive. The proposed three-ports DC-DC converter will be used in so many real applications such as hybrid cars, communication towers and solar arrays.

\section{Innovation in the Power Stage}

Single converter stage interface of three power terminals is targeted: a source, a load, and a bidirectional terminal for power storage. Isolation through a transformer is required for the load terminal for:

1) Design flexibility with high voltage step-up/down ratios

2) Flexible series/parallel converter connection in modular designs, and compatibility with NASA's Series

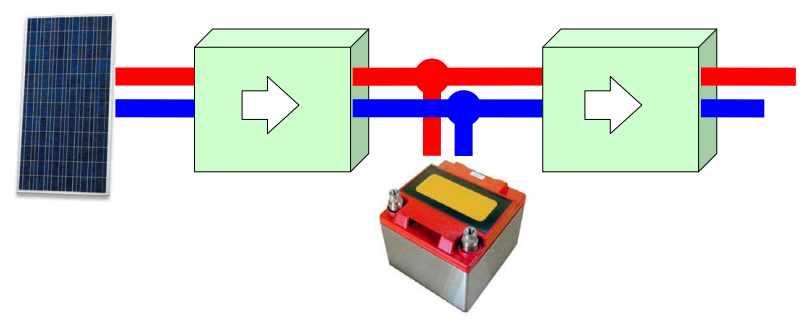

Figure 1. Two stage solar power system.

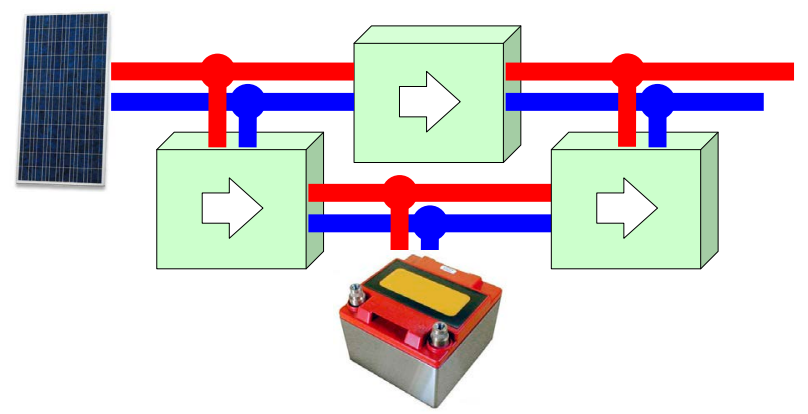

Figure 2. Three-converter solar power system. 
Connected Boost Regulator (SCBR) concept [10], as well as the Power Electronics Building Blocks (PEBB's) approach [11].

3) User/operator safety

Achieving the power management objectives using a two-converter approach requires a minimum of one non-isolated and one isolated topology. The addition of a third converter helps increase efficiency, and requires an additional isolated converter. Options for converter selection are summarized below. Note that buck-boost and fly-back converters are not considered since they are not practically suitable for medium and high power applications due to large inductor/transformer current values, and high output capacitor current ripple.

The use of a buck or a boost, together with a push-pull converter, allows a small switch and diode count, but requires too many magnetic components. The transformer required has a center-tapped input, reducing the utilization efficiency of the core. Replacing the push-pull with a half-bridge or an active clamp forward circuit simplifies the transformer, but requires the addition of a storage capacitor. The full-bridge option is more suitable for higher power levels and lower input voltages at the cost of a high active switch count.

\section{Analysis, Modeling and Control of Three-Prot DC-DC Converter}

The three-port DC-DC Converter, shown in Figure 3, is the modified version of PWM half bridge converter that includes three basic circuit stages within a constant-frequency switching cycle to provide two independent control variables. The switching sequence shown in the figure ensures a clamping path for the energy of the leakage inductance of the transformer at all times. This energy is further utilized to achieve zero-voltage switching (ZVS) for all primary switches for a wide range of source and load conditions.

Full-bridge converters are more suitable for higher power applications, typically above $1 \mathrm{~kW}$. Applying the same concept of dual use of the phase legs, a three-terminal topology can be derived from the full-bridge circuit. The bidirectional terminal of this topology is controlled by changing the duty cycle of the phase legs to achieve the target voltage ratio. The two phase legs need to maintain equal duty cycles. The load terminal is controlled by phase shifting the driving waveforms of these two phase legs relative to each other, just like the ZVT fullbridge topology.

The steady-state voltage relationships, assuming CCM operation of the load filter inductor, are given by:

$$
\begin{gathered}
V_{b i}=D \cdot V_{i n} \\
V_{o}=2 \cdot n \cdot \phi \cdot V_{i n},
\end{gathered}
$$

given that

$$
0 \leq \phi \leq \min (D, 1-D)
$$

where:

$D$ is the duty cycle of each phase leg;

$\phi$ is the phase shift between the two phase leg waveforms.

This topology operates as boost-derived push-pull converter when supplying energy from the bidirectional terminal to the load. This topology is thus an attractive alternative for low voltage storage devices since it saves

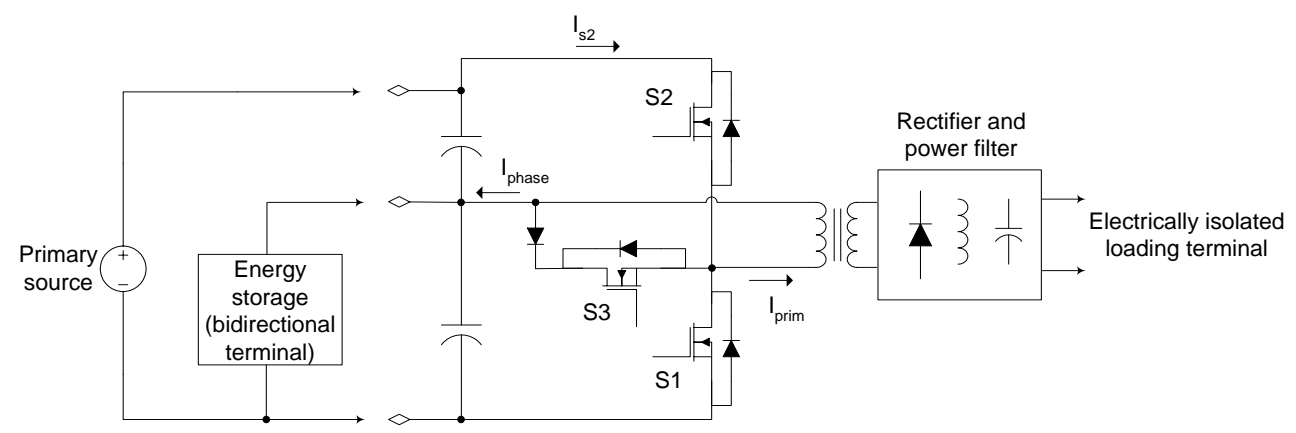

Figure 3. Three-port DC-DC converter topology. 

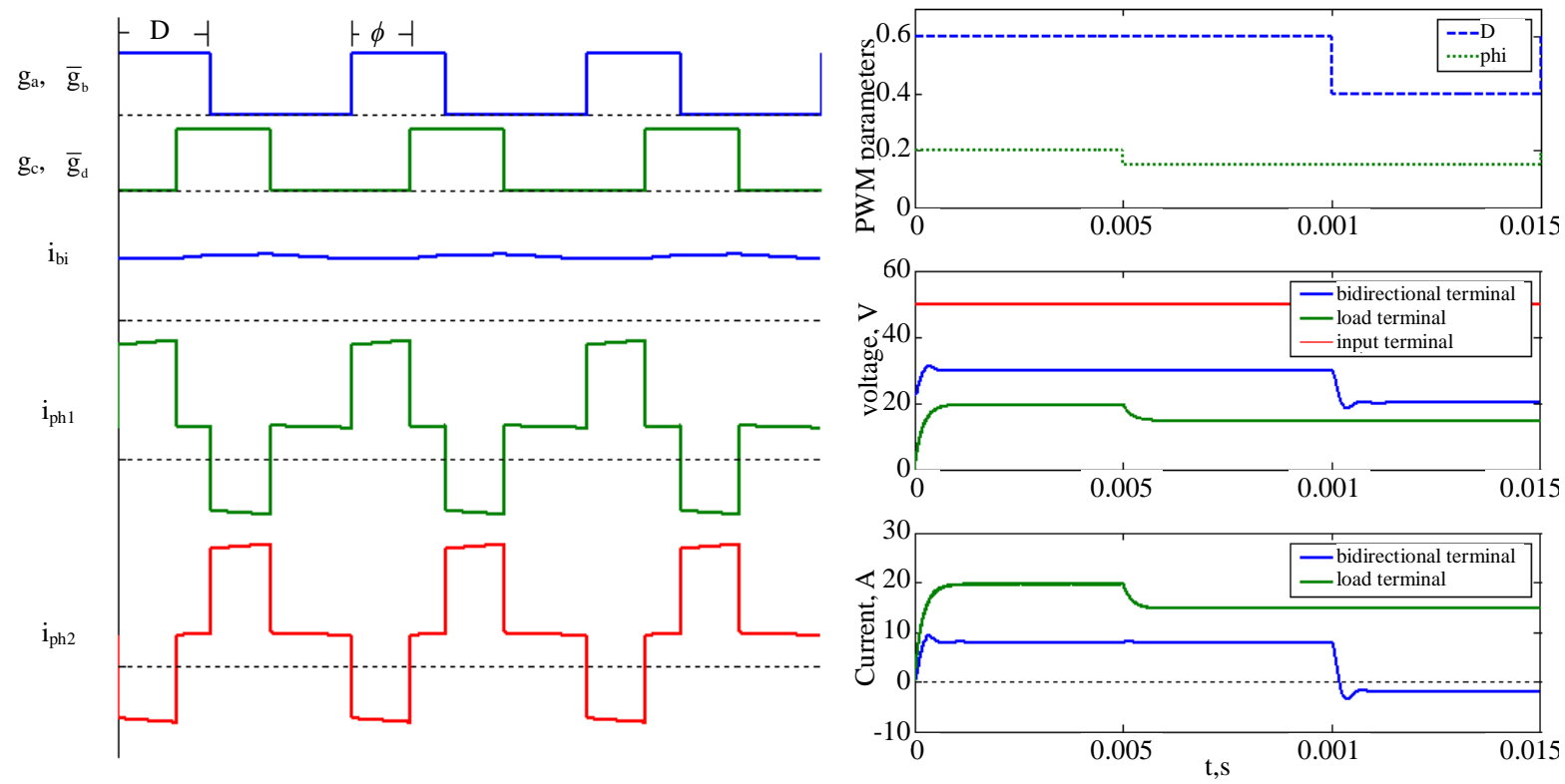

Figure 4. Simulation waveforms: (a) Basic switching waveforms; (b) Terminal voltages and currents.

on the turns-ratio of the transformer and simplifies its design. The center-tapped transformer and the bidirectional terminal inductor assembly are suitable for being wound on a single core, in an integrated magnetic fashion.

PLECS simulation results are shown in Figure 4. Again, control was adjusted at $t=5 \mathrm{~ms}$ and at $10 \mathrm{~ms}$ to independently control the voltages of the load and bidirectional terminals. Converter ability to handle negative current in the bidirectional terminal was verified. The small signal model is tailored for deriving multi-port DC-DC converters under different modes of operation. It is difficult to define different modes since there are various modes of operation. After we define the mode, a competitive method is used to realize smooth and seamless mode transition.

As we mentioned before, the converter topologies proposed in this work present new control challenges to the power electronics community. The proposed topologies call for a PWM that creates switching waveforms that have two independent variables, based on two error signals, derived by two feedback controllers, each tightly regulating a different control variable. Also we mentioned that digital control is a strong candidate for such topologies because of its flexibility, and the ability to perform complicated feed-forward and loop decoupling functions. Digital control is an indispensable tool for the development phase, since it is capable of realizing a variety of customized modulator structures. The digital control architecture that is used to regulate different power ports is shown in Figure 5. There are many control loops named as follows,

1) Input voltage regulation (IVR),

2) Output voltage regulation (OVR),

3) Battery voltage regulation (BVR), and

4) Battery current regulation (BCR).

\section{Bifurcation and Chaos Theory Applied to DC-DC Converters}

Bifurcation theory is introduced to nonlinear dynamics by a Frenchman named Poincare. It is used to indicate a qualitative change in the features of the system, such as the number and the type of solutions, under the variation of one or more parameters on which the considered system depends, Nayfeh and Balachandran [18].

\section{Bifurcation and Chaos Applied to Buck Converter}

In this section, the iteration mapping technique is applied, using a MATLAB code, on DC/DC buck designs. In order to design a buck converter, the following input-output parameters are needed: Input voltage $\left(V_{\text {in }}\right)$, output voltage $\left(V_{0}\right)$, power rating $\left(P_{0}\right)$, switching frequency $\left(f_{s}\right)$, output voltage ripple $\left(\Delta V_{0}\right)$, and inductor current ripple 
$(\Delta I)$. Then, the low pass filter parameters $(L$ and $C$ ) can be calculated using the formulas in [19]. Depending on the operation mode, either CCM or DCM, the value of the inductance is determined. The derivation shown in [20] is for a CCM operation mode, and it isn't valid for DCM operation mode. A third operating mode is added to the previous two operating modes, and thus, a new derivation should be done. The capacitance value determines the amount of the high frequency ripple that is imposed on the output DC voltage. Table 1 lists the buck parameters used in [21]. These values were used in this paper as a study case for nonlinearity test. The results showed that the buck converter exhibit bifurcation and then a chaos behavior as the input voltage changes.

Figure 6 shows the inductor current $\left(i_{L}(t)\right)$ as the input voltage changes. The current remains stable until $V_{\text {in }}$ reaches 9.85 Vdc. Then, it enters a period-doubling (bifurcation) region, and period-4 after that. Finally, a chaotic behavior was experienced. The same behavior happened to the output voltage $\left(v_{C}(t)\right)$ as shown in Figure 7. Again, both the inductor current and the output voltage showed a chaotic behavior.

\section{Three-Port Half-Bridge Converter}

This section introduces the three-port topology. As shown in Figure 8, it is a modified version of PWM half bridge converter which includes three basic circuit stages within a constant frequency switching cycle to provide two independent control variables, namely duty-cycles $d_{1}$ and $d_{2}$ which are to control $S 1$ and $S 2$, respectively.

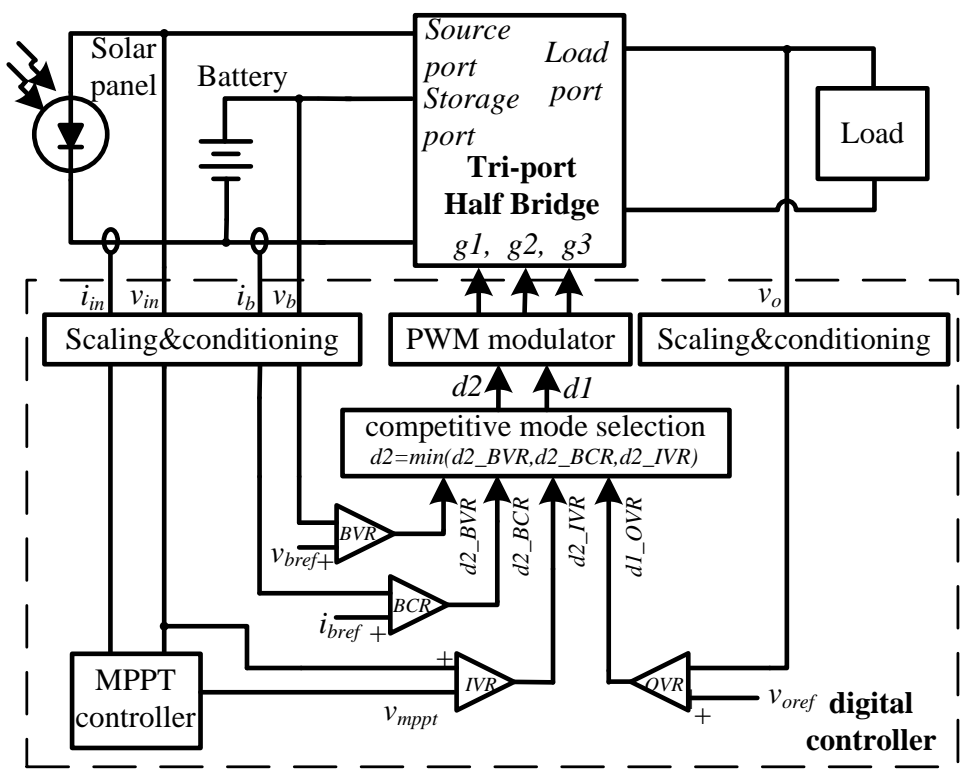

Figure 5. Digital controller of multi-port converter for MPPT.

Table 1. Voltage-mode controlled DC/DC buck converter parameters.

\begin{tabular}{lc}
\hline Component & Value \\
\hline Resistor $(R)$ & $5.4 \Omega$ \\
Inductor $(L)$ & $1 \mathrm{mH}$ \\
Capacitor $(C)$ & $22 \mu \mathrm{F}$ \\
The reduction gain $(q)$ & 1 \\
The gain $(A)$ & 1 \\
Upper limit of the ramp signal $\left(V_{U}\right)$ & $5.7 \mathrm{~V}$ \\
Lower limit of the ramp signal $\left(V_{L}\right)$ & $0.6 \mathrm{~V}$ \\
Reference voltage & $5.2 \mathrm{~V}$ \\
\hline
\end{tabular}




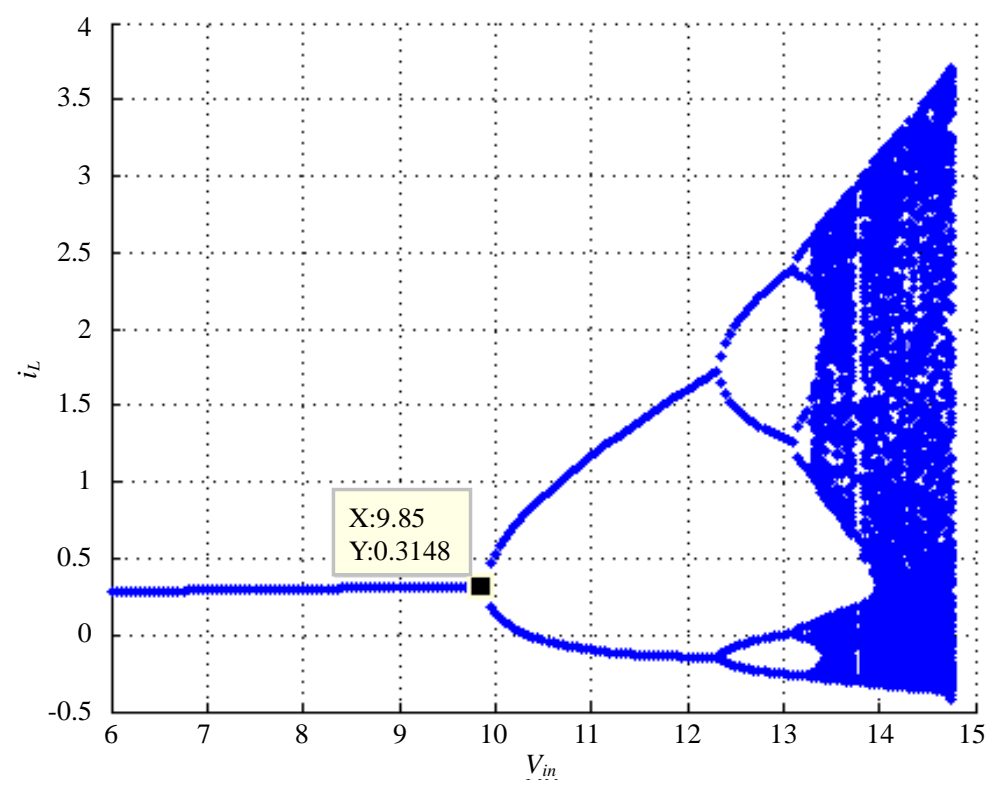

Figure 6. Inductor current $\left(i_{L}(t)\right)$ versus the input voltage $\left(V_{i n}\right)$ changes as a control paramter.

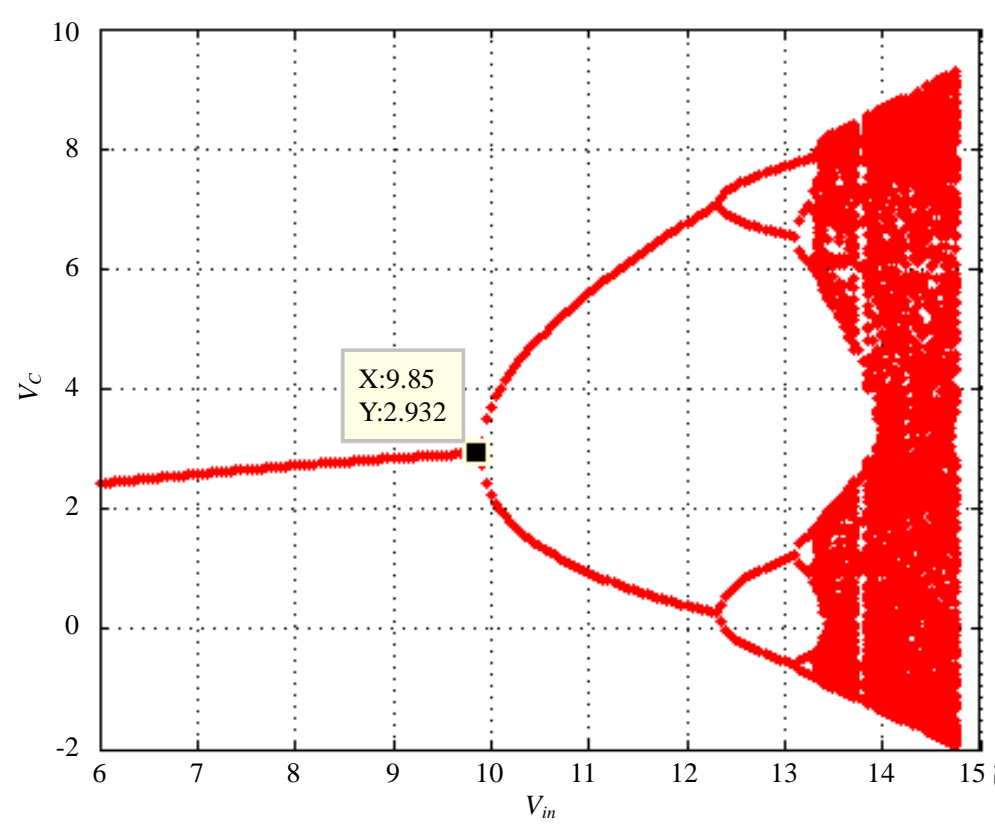

Figure 7. Output voltage $\left(v_{C}(\mathrm{t})\right)$ versus the input voltage $\left(V_{\text {in }}\right)$ changes as a control paramter.

This allows tight control over two of the converter ports, while the third port provides the power balance in the system. The switching sequence ensures a clamping path for the energy of the leakage inductance of the transformer at all times. This energy is further utilized to achieve zero-voltage switching (ZVS) for all primary switches for a wide range of source and load conditions. The simulation will be discussed as follows.

\subsection{Analysis}

Assuming an ideal lossless converter, the steady-state voltage governing relations between different port voltages can be determined by equating the voltage-second product across the converter's two main inductors to zero. 


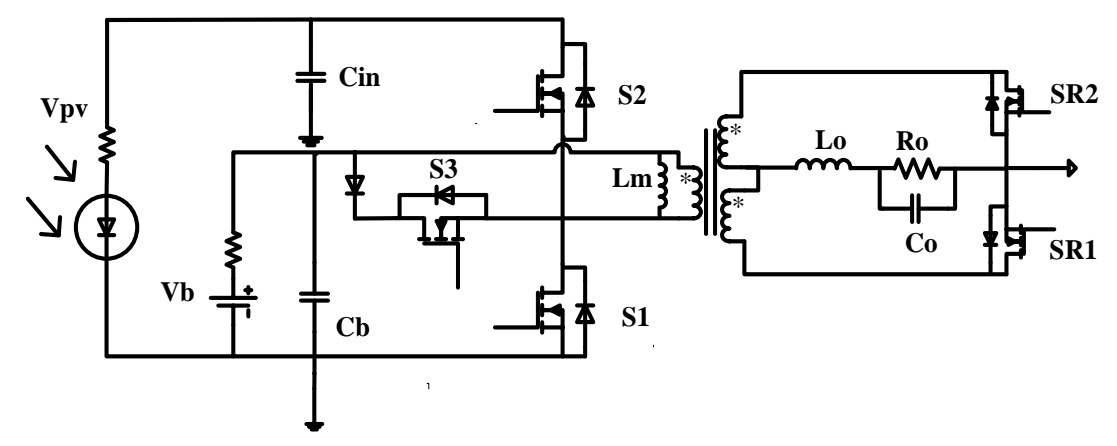

Figure 8. Three-port modified half-bridge converter topology.

First, using volt-second balance across the primary transformer magnetizing inductance, when operating in continuous conduction mode (CCM), we have:

$$
V_{b} \cdot D_{1}=\left(V_{p v}-V_{b}\right) \cdot D_{2}
$$

With $V_{p v}=V_{C i n}+V_{C b}$, and $V_{b}=V_{C b}$, the voltage at the bidirectional port, $V_{b}$, may be given by:

$$
V_{b}=\frac{D_{2}}{D_{1}+D_{2}} V_{p v}
$$

where $V_{p v}$ is the voltage of the input port, $D_{1}$ and $D_{2}$ are the duty-cycles of $S_{1}$ and $S_{2}$, respectively, and $T$ is the duration of the switching cycle. Assuming CCM operation, the volt-second balance across the load filter inductor yields:

$$
\begin{aligned}
& D_{1} T\left(n V_{b}-V_{o}\right)+D_{2} T\left(n V_{p v}-n V_{b}-V_{o}\right)-\left(1-D_{1}-D_{2}\right) T V_{o}=0 \\
& V_{o}=2 \frac{D_{1} D_{2}}{D_{1}+D_{2}} n V_{p v}
\end{aligned}
$$

where $n$ is the turn ratio of the transformer, and $V_{o}$ is the load-port voltage. This can also be re-written as:

$$
V_{o}=2 D_{1} n V_{b}
$$

Assuming a lossless converter, steady-state port currents can be related by applying the power conservation principle as follows:

$$
V_{p v} I_{p v}=V_{b} I_{b}+V_{o} I_{o}
$$

where $I_{p v}, I_{p v}, I_{o}$ are the average input, bidirectional battery, and load currents, respectively.

\subsection{Operational Mode Definition}

Having different operational modes is one of the unique features for this three-port half-bridge converter. Two assumptions are made to simplify analysis: 1) Load power is assumed to be constant; 2) Battery over-discharge is ignored because PV arrays and batteries are typically over-sized in satellites to provide some safety margins. Four stages in satellite's one orbit cycle yield two basic operational modes as follows.

In Battery-balanced Mode (Mode 1), the load voltage is tightly regulated, and the solar panel operates under MPPT control to provide maximum power. The battery preserves the power balance for the system by storing unconsumed solar power, or providing the deficit during high load intervals. Therefore, the solar array can be scaled to provide average load power while the battery provides the deficit during peak power of load, which is attracting to reduce solar array mass.

In Battery-regulation Mode (Mode 2), the load is regulated and sinks less power than is available, while the battery charge rate is controlled to prevent overcharging. This mode stops to start Mode 1 when the load increases beyond available solar power. That is, battery parameter falls below either maximum voltage setting or 
maximum current setting.

Three-port converter can achieve MPPT, battery charge control and load regulation depending on available solar power, battery state of charge and load profile. In Stage I, battery acts as the exclusive source. In Stages II \& III, solar power is maximized to decrease battery state of discharge in Stage II for initial insulation period and then to increase battery state of charge in Stage III for increased insulation period. In Stage IV, battery charge control is applied to prevent battery over-charging and extend battery service life.

\section{Experimental Results}

Figure 9 illustrates a $200 \mathrm{~W}$ prototype. Power stage's input port, battery port and output port are marked as in the prototype photo. It consists of two boards, power stage board and controller board.

The values of circuit parameters used in the simulation and experimental circuit are listed in the following Table 2.

The mode transition and control structure for both operational modes are tested through a $200 \mathrm{~W}$ prototype. Power stage's input port, battery port and output port are marked as in the prototype photo. It consists of two boards, power stage board and controller board. All feed-back control loops' compensators are implemented by a direct digital design method. Figure 10 shows the waveforms when the power is transferred from input port to the output load port, while battery port is chosen to be open. Output inductor current ILo has four stages, and transformer magnetizing average current Ipri is zero, implying no battery power. Figure 11 shows the waveforms when the most power is transferred from input port to the battery port. Output inductor current ILo average represents the load current, which is zero. Therefore, negative ILo is observed. Ipri average value represents the battery current, which is 7A.

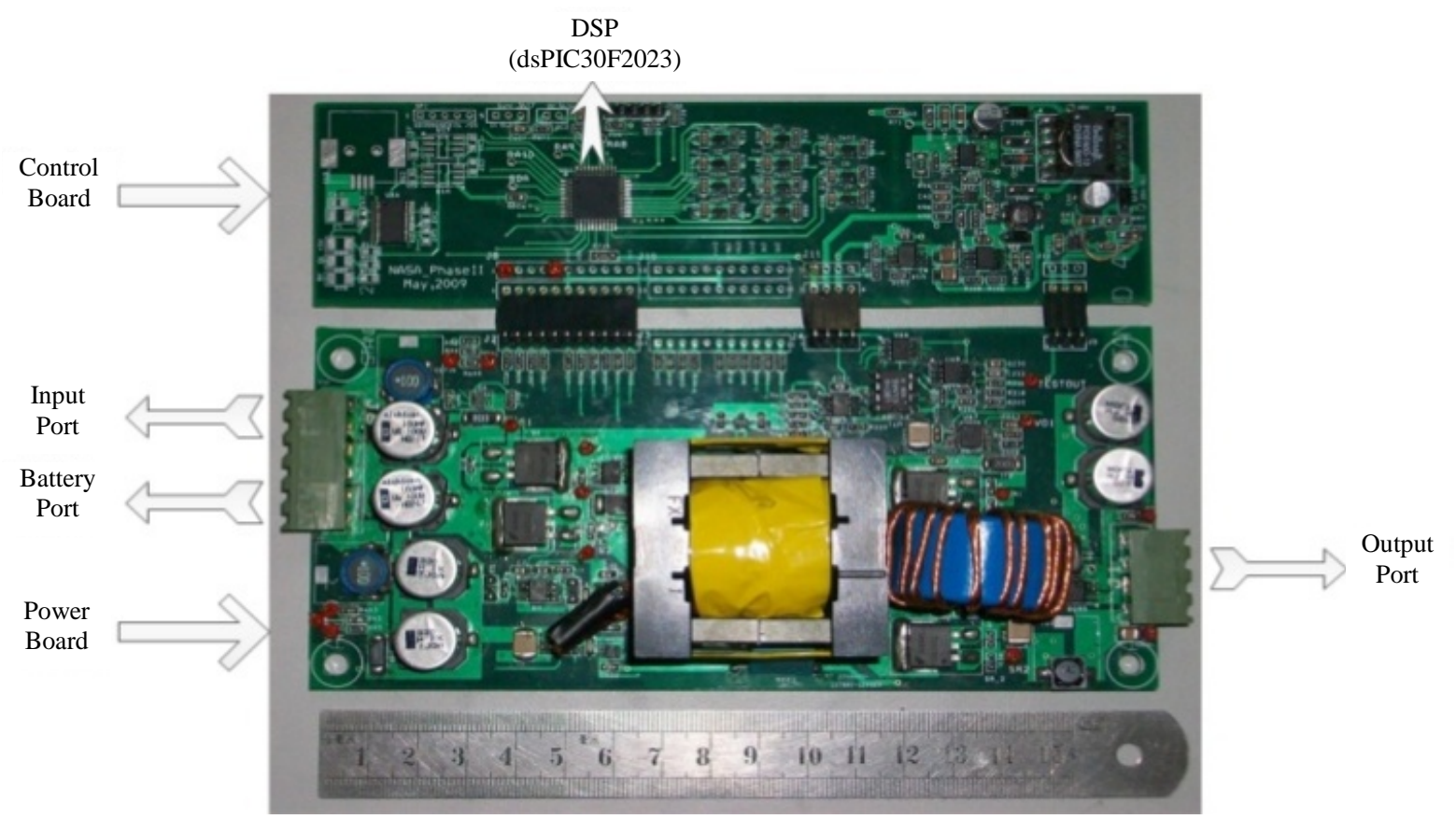

Figure 9. Prototype photo of three-port converter which consists of one controller board andone power board.

Table 2. Values of circuit parameters.

\begin{tabular}{ccccc}
\hline Output inductor & $L_{o}$ & $65 \mu \mathrm{H}$ & Output voltage & $V_{o}$ \\
Magnetizing inductor & $L_{m}$ & $45 \mu \mathrm{H}$ & Input voltage & $V_{\text {in }}$ \\
Output filter capacitor & $C_{o}$ & $680 \mu \mathrm{F}$ & Battery voltage & $V_{b}$ \\
Battery port filter capacitor & $C_{1}$ & $680 \mu \mathrm{F}$ & Input port filter capacitor & $C_{2}$ \\
\hline
\end{tabular}




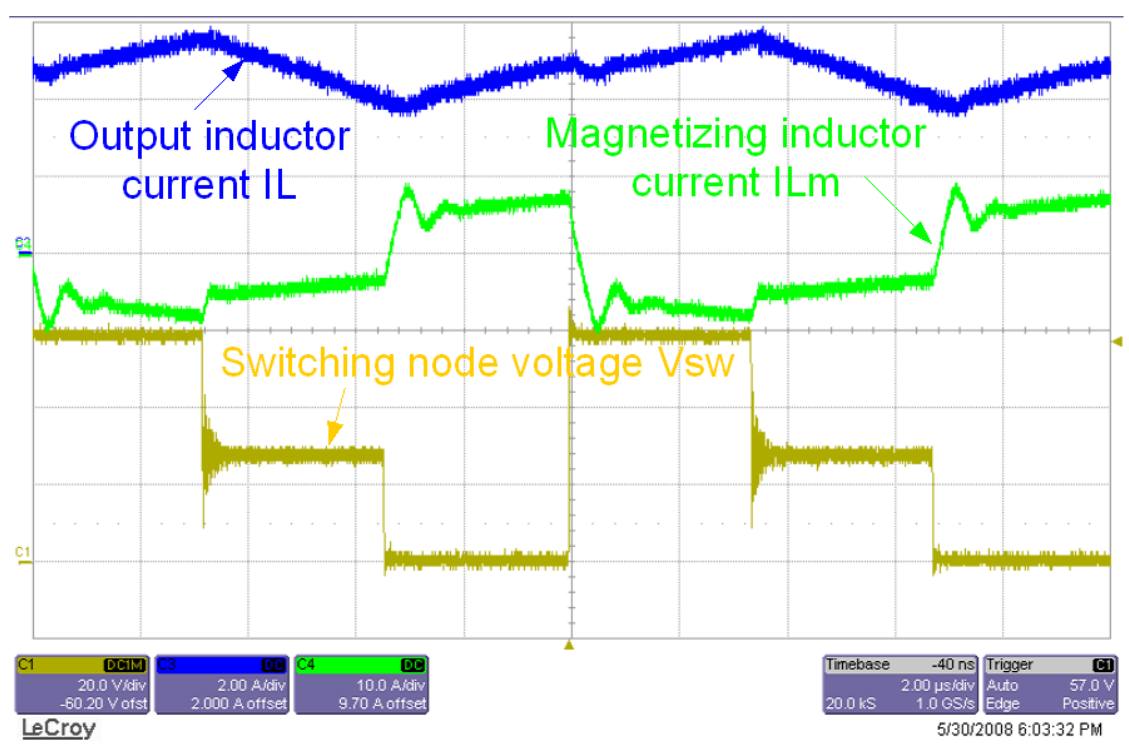

Figure 10. Loading output port when the battery current is zero.

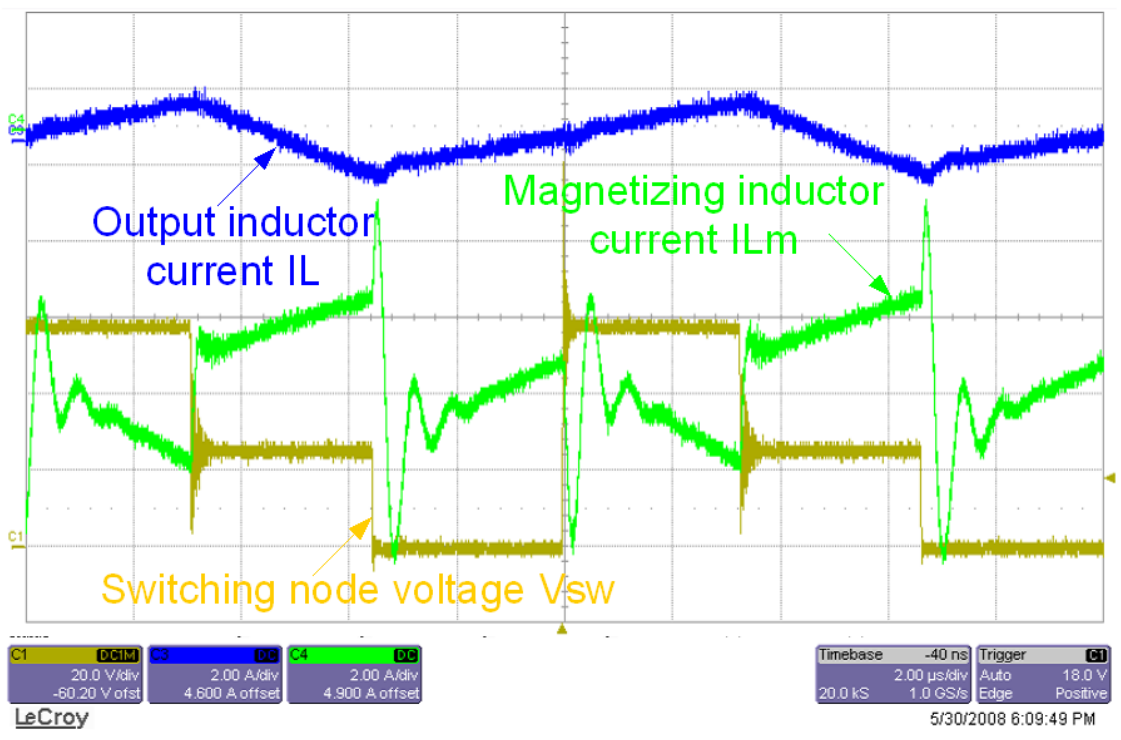

Figure 11. Loading battery port when the output current is zero.

Figures 12-14 show the gating signal $V_{g s}$ and switching node $V_{s w}$ waveforms of the switches $S_{1}, S_{2}$ and $S_{3}$, respectively. The conclusion is that all three main switches can achieve ZVS, because they all turn on after their $V_{d s}$ go to zero.

Figures 15-17 show the efficiency curves when the power is transferred from one port to the other port. The highest efficiency is observed when the power is transferred from solar port to battery port. The reason is that this operation has minimal transformer losses, since the power is exchanged within the primary side.

Figure 17(a) shows mode transition from Battery-balanced mode (Mode 1) to Battery regulation mode (Mode 2) when battery maximum voltage setting of $29 \mathrm{~V}$ is reached. Solar panel first works under IVR control with MPPT to maximize solar power, then it is forced to operate in solar panel's voltage source region when IVR loses control and BVR takes control over $d_{2}$, so the input port provides power balance after the transition into battery regulation mode. It can be seen that the transition of the proposed competitive method is smooth and causes no oscillation that is experienced with the sudden transition of duty cycles. The battery voltage has $0.5 \mathrm{~V}$ overshoot, and input voltage has $2.5 \mathrm{~V}$ overshoot, both are within acceptable range according to specifications. 


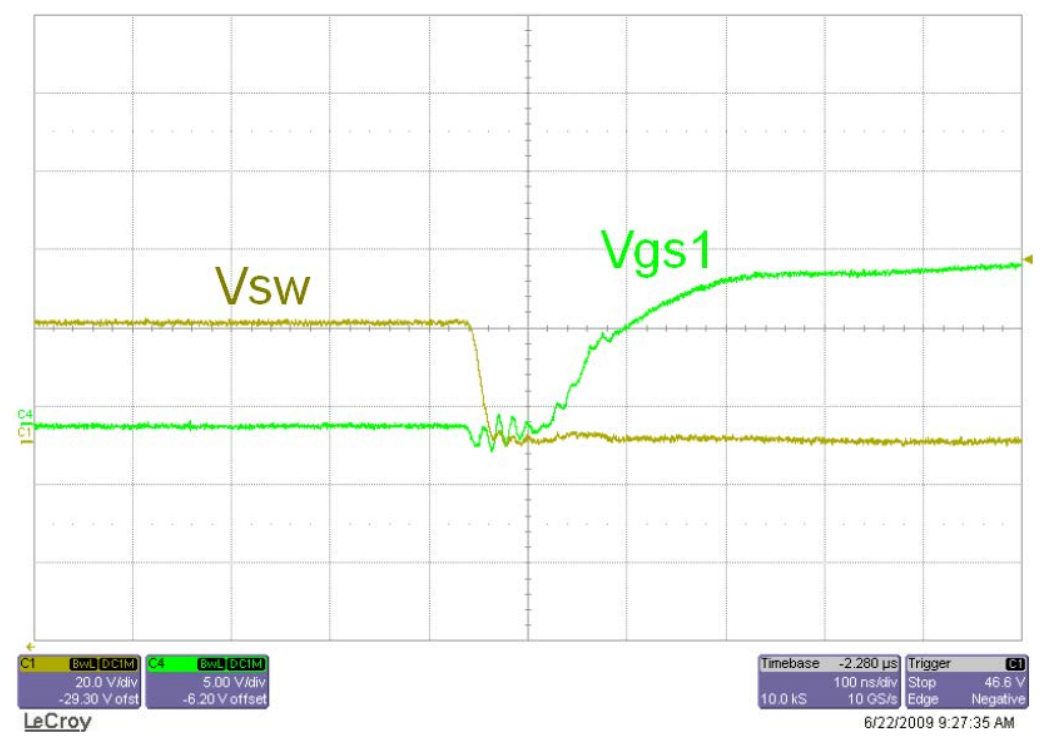

Figure 12. ZVS for $S_{1}$.

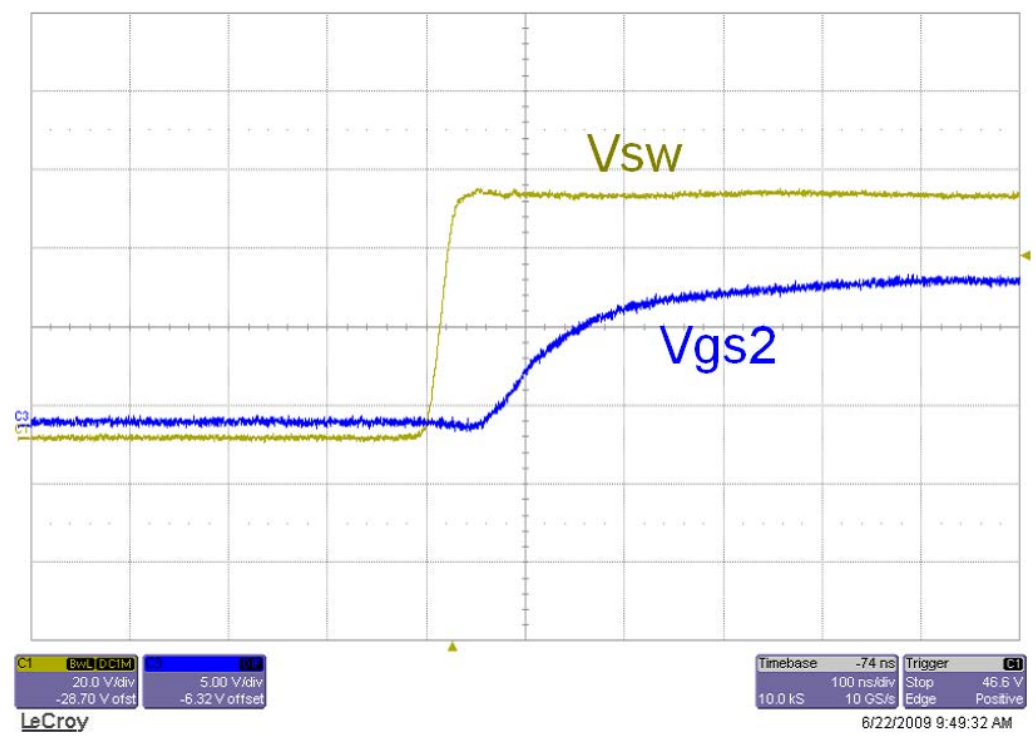

Figure 13. ZVS for $S_{2}$.

Figure 18(b) gives Mode 2 to Mode 1 transition when load level suddenly increases to force the battery to source instead of sink. Since battery voltage setting cannot be met during discharging, $d_{2}$ will be controlled by IVR since BVR quickly loses control, and solar panel quickly reacts to work under MPPT control so as to harvest maximum available solar power, and battery becomes to provide the power balance in Mode 1.

Figure 18(a) shows the input voltage, battery voltage and output voltage response to a load transient between 1A and 3A in Battery-regulation Mode. Output voltage transient response of 500 us settling time is much faster than battery voltage settling time of $40 \mathrm{~ms}$ because OVR band width is ten times larger than that of BVR. Input voltage changes according to load level changes because input port provides power balance. Figure 19(b) demonstrates the system transient response in Battery-balanced Mode when MPPT is active. The load step is from $1 \mathrm{~A}$ to $5 \mathrm{~A}$. Input voltage response to load transient of $20 \mathrm{~ms}$ settling time is much slower than output voltage settling time of 500 us because IVR crossover frequency is set at one tenth of that of OVR. Input voltage remains uninterrupted at around MPP even during load changes, which is the unique feature of three-port converters, because MPPT and load regulation cannot be achieved simultaneously by conventional two-port converter. 


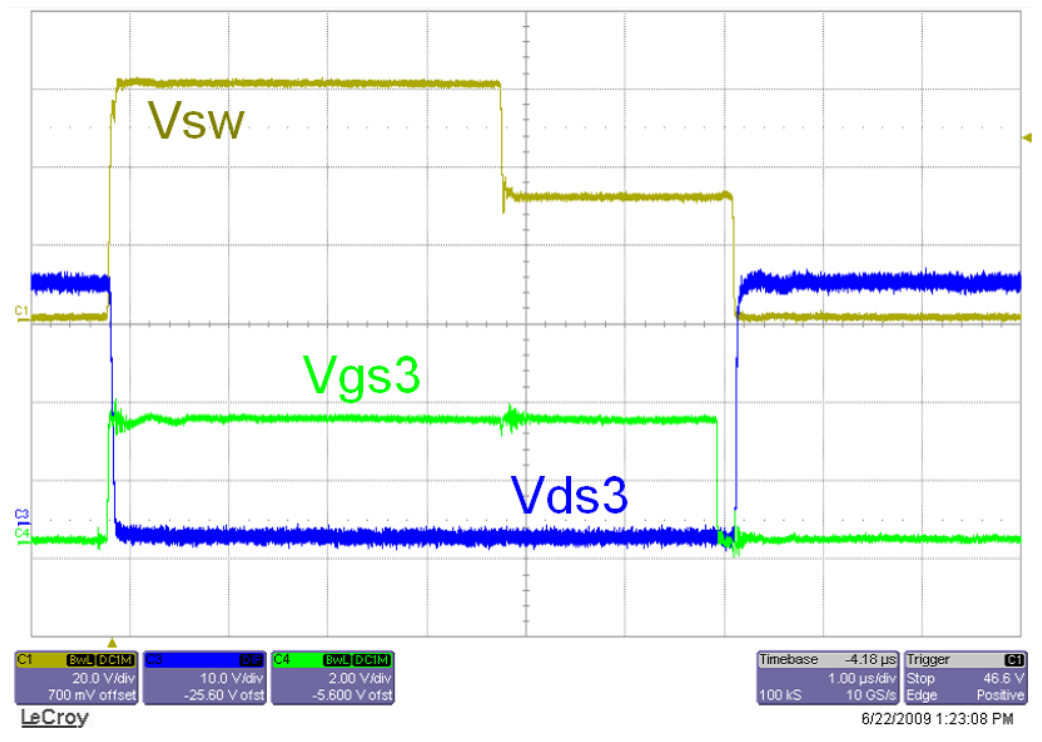

Figure 14. ZVS for $S_{3}$.

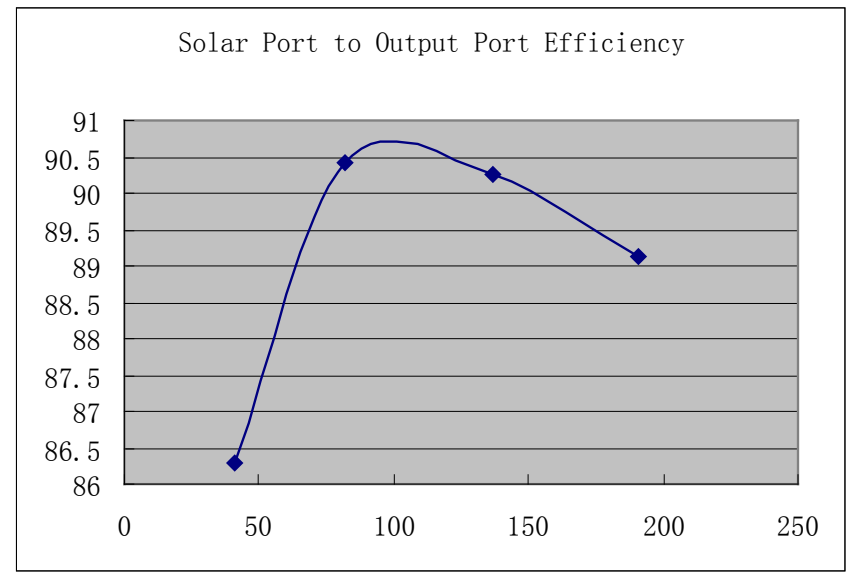

Figure 15. The efficiency when the power is transferred from solar port to output port.

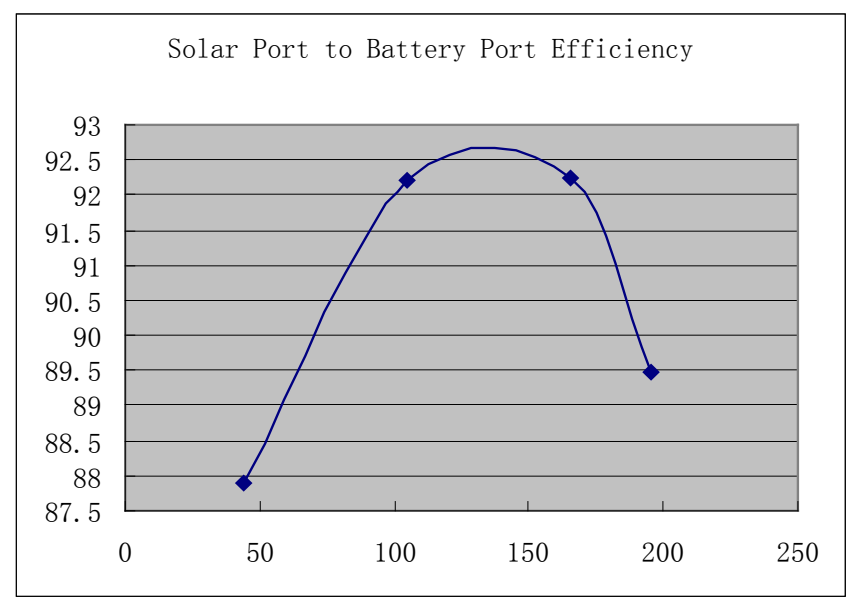

Figure 16. The efficiency when the power is transferred from solar port to battery port. 


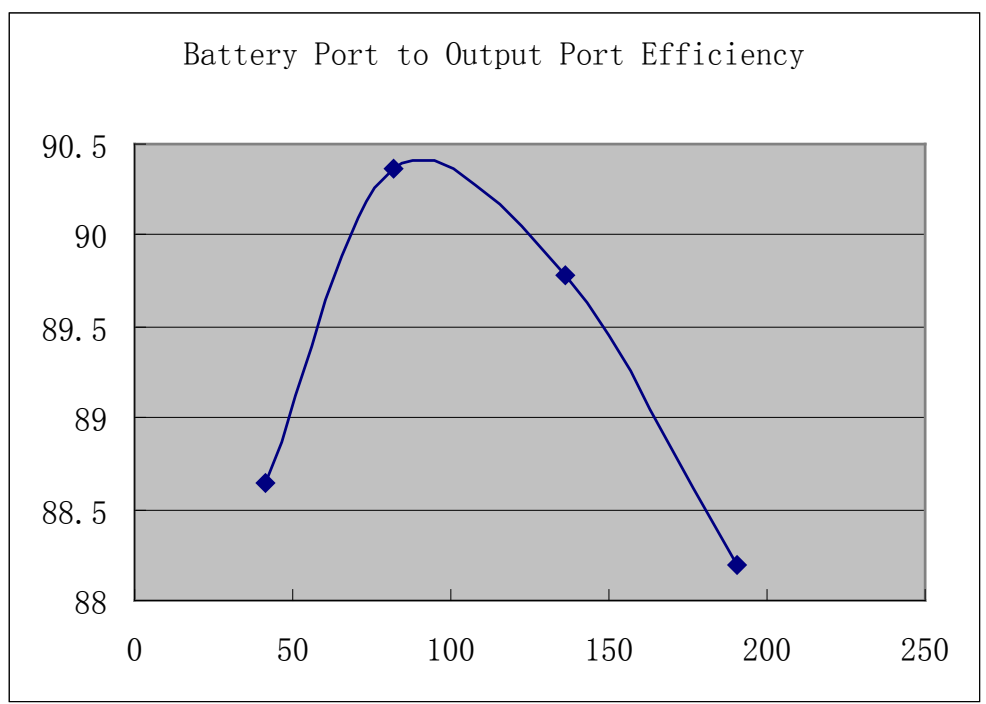

Figure 17. The efficiency when the power is transferred from battery port to output port.

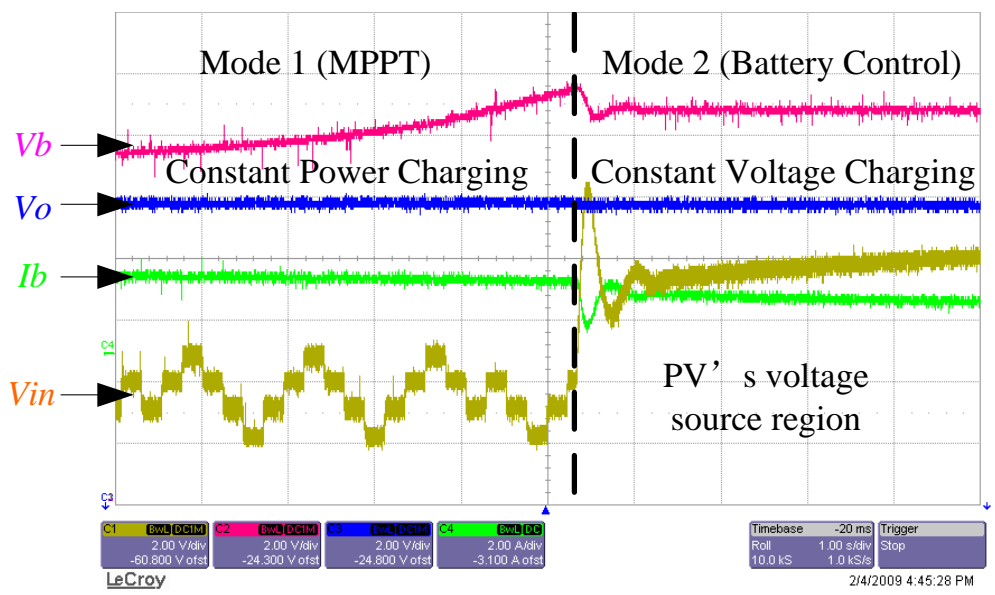

(a)

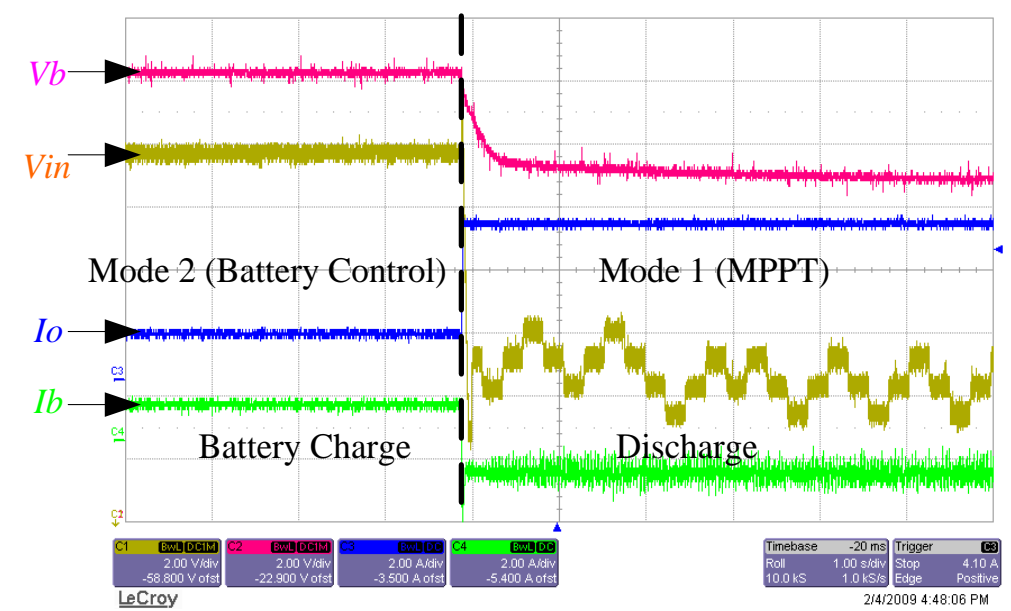

(b)

Figure 18. Autonomous mode transition, (a) Mode 1 to Mode 2; (b) Mode 2 to Mode 1. 


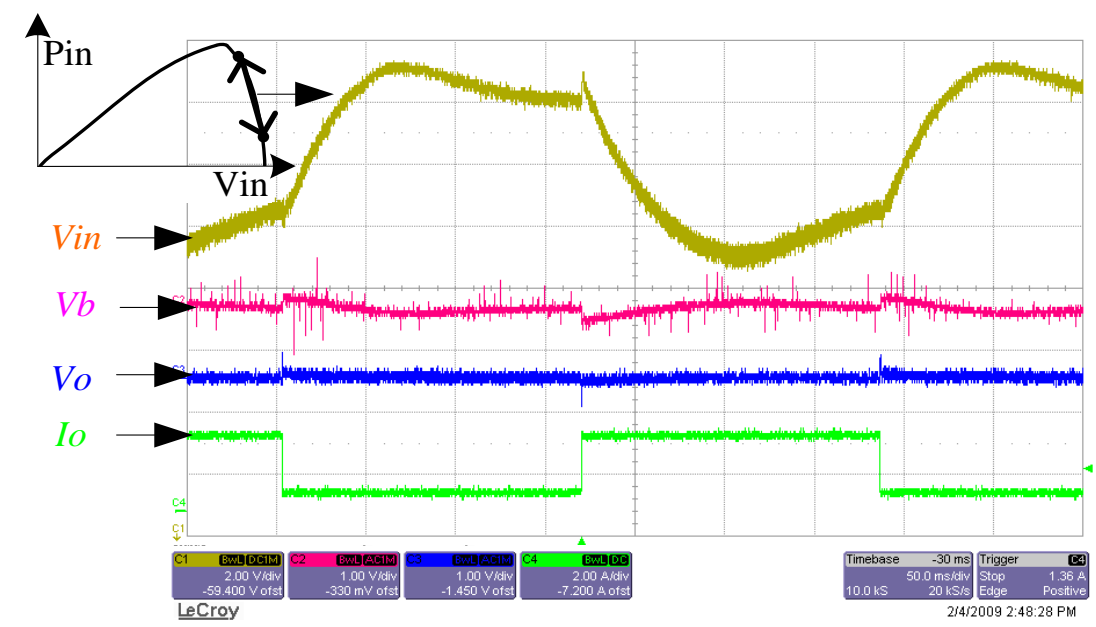

(a)

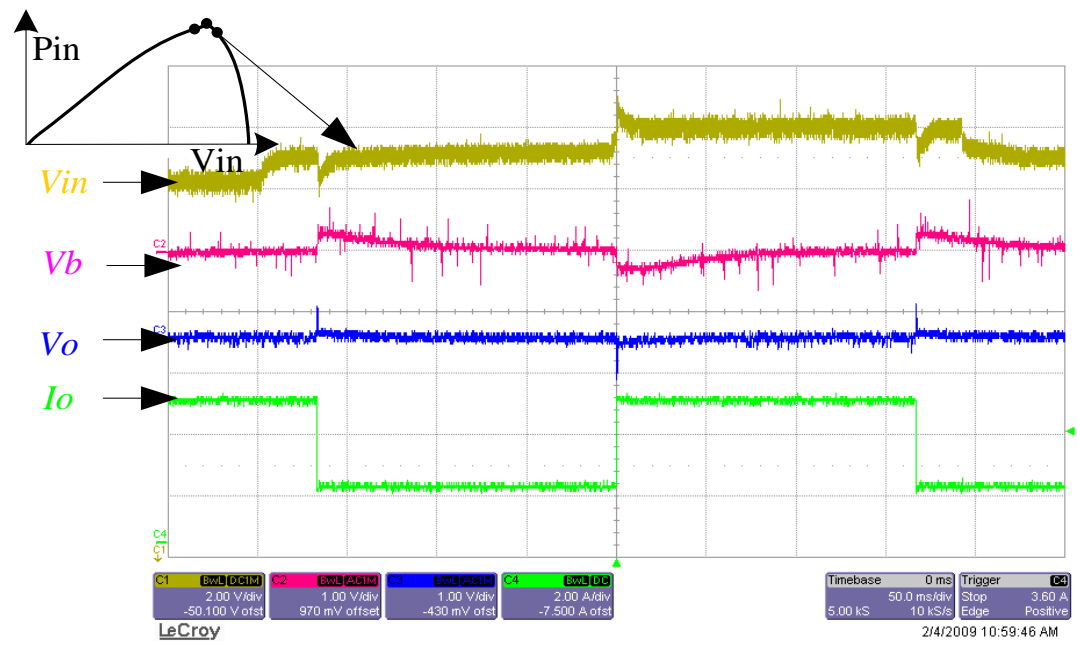

(b)

Figure 19. (a) Battery-regulation Mode load step response; (b) Battery-balanced Modeload step response.

\section{Conclusion}

In this paper, a new three-port converter interfacing the renewable energy input, battery terminal as well as output terminal is proposed. Its operation principle is analyzed in details and a small signal model is derived to guide the controller design. Simulation was carried out to verify the proposed converter. A nonlinear simulation was carried out and the study shows that the converter is experiencing chaotic behavior because of some changes in the input voltage $V_{i n}$. Experimental results show that the proposed converter has the capability of regulating the output voltage while maintaining the power balance between inputs and output power, which is very suitable for renewable energy applications.

\section{Acknowledgements}

This work was supported by the National Science, Technology and Innovation Plan (NSTIP) through the Science and Technology Unit (STU) at Taibah University, Al Madinah Al Munawwarah, KSA, with the grant number 08-ENE416-05.

\section{References}

[1] Capel, A. (1998) The Power System of the Multimedia Constellation Satellite for the Skybridge Missions. Proceedings 
of IEEE Power Electronics Specialist Conference, 1913-1930.

[2] Brandhorst, H.W., O’Neill, M.J. and Eskenazi, M. (2003) Photovoltaic Options for Increased Satellite Power at Lower Cost. Proceedings of IEEE Photovoltaic Energy Conversion, 849-852.

[3] Jang, S. and Choi, J. (2008) Energy Balance Analysis of Small Satellite in Low Earth Orbit (LEO). Proceedings of IEEE Power and Energy Conference, 967-971.

[4] Middlebrook, R.D. and Cuk, S. (1977) A General Unified Approach to Modeling Switching-Converter Power Stages. International Journal of Electronics, 42, 521-550. http://dx.doi.org/10.1080/00207217708900678

[5] Cuk, S. (1976) Modeling, Analysis, and Design of Switching Converters. Ph.D. Thesis, California Institute of Technology, Pasadena.

[6] Di Napoli, A., Crescimbini, F., Solero, L., Caricchi, F. and Capponi, F.G. (2002) Multiple-Input DC-DC Power Converter for Power-Flow Management in Hybrid Vehicles. Proceedings of IEEE Industry Application Conference, 15781585.

[7] Jiang, W. and Fahimi, B. (2009) Multi-Port Power Electric Interface for Renewable Energy Sources. IEEE 2009 Applied Power Electronics Conference, 347-352.

[8] Imes, W.G. and Rodriguez, F.D. (1994) A Two-Input Tri-State Converter for Spacecraft Power Conditioning. Proceedings of AIAA International Energy Conversion Engineering Conference, 163-168.

[9] Rodriguez, F.D. and Imes, W.G. (1994) Analysis and Modeling of a Two-Input DC/DC Converter with Two Controlled Variables and Four Switched Networks. Proceedings of AIAA International Energy Conversion Engineering Conference, 322-327.

[10] Dobbs, B.G. and Chapman, P.L. (2003) A Multiple-Input DC-DC Converter Topology. IEEE Power Electronics Letters, 1, 6-9.

[11] Benavides, N.D. and Chapman, P.L. (2005) Power Budgeting of a Multiple-Input Buck-Boost Converter. IEEE Transactions on Power Electronics, 20, 1303-1309. http://dx.doi.org/10.1109/TPEL.2005.857531

[12] Matsuo, H., Lin, W.Z., Kurokawa, F., Shigemizu, T. and Watanabe, N. (2004) Characteristics of the Multiple-Input DC-DC Converter. IEEE Transactions on Industrial Electronics, 51, 625-631.

[13] Solero, L., Caricchi, F., Crescimbini, F., Honorati, O. and Mezzetti, F. (1996) Performance of a 10 kW Power Electronic Interface for Combined Wind/PV Isolated Generating Systems. Annual IEEE Power Electronics Specialists Conference, 2, 1027-1032.

[14] Solero, L., Lidozzi, A. and Pomilio, J.A. (2004) Design of Multiple-Input Power Converter for Hybrid Vehicles. IEEE Applied Power Electronics Conference and Exposition, 2, 1145-1151.

[15] Su, G.J. and Peng, F.Z. (2005) A Low Cost, Triple-Voltage Bus DC-DC Converter for Automotive Applications. IEEE Applied Power Electronics Conference and Exposition, 2, 1015-1021.

[16] Peng, F.Z., Li, H., Su, G.J. and Lawler, J.S. (2004) A New ZVS Bidirectional DC-DC Converter for Fuel Cell and Battery Application. IEEE Transactions on Power Electronics, 19, 54-65. http://dx.doi.org/10.1109/TPEL.2003.820550

[17] Tao, H., Kotsopoulos, A., Duarte, J.L. and Hendrix, M.A.M. (2005) Multi-Input Bidirectional DC-DC Converter Combining DC-Link and Magnetic-Coupling for Fuel Cell Systems. IEEE Industry Applications Conference, 3, 2021-2028.

[18] Nayfeh, A.H. and Balachandran, B. (1995) Applied Nonlinear Dynamics. John Wiley, New York. http://dx.doi.org/10.1002/9783527617548

[19] Chakrabarty, K., Poddar, G. and Banerjee, S. (1996) Bifurcation Behavior of the Buck Converter. IEEE Transactions on Power Electronics, 11, 439-447. http://dx.doi.org/10.1109/63.491637

[20] Harb, A. and Harb, S. (2012) Chaos and Bifurcation of DC-DC Buck Convertor. Renewable Energy Congress, Sousse, 20-22 December 2012.

[21] Maity, S., Tripathy, D., Bhattacharya, T.K. and Banerjee, S. (2007) Bifurcation Analysis of PWM-1 Voltage-ModeControlled Buck Converter Using the Exact Discrete Model. IEEE Transactions on Circuits and Systems I, 54, 11201130 . 
Scientific Research Publishing (SCIRP) is one of the largest Open Access journal publishers. It is currently publishing more than 200 open access, online, peer-reviewed journals covering a wide range of academic disciplines. SCIRP serves the worldwide academic communities and contributes to the progress and application of science with its publication.

Other selected journals from SCIRP are listed as below. Submit your manuscript to us via either submit@scirp.org or Online Submission Portal.
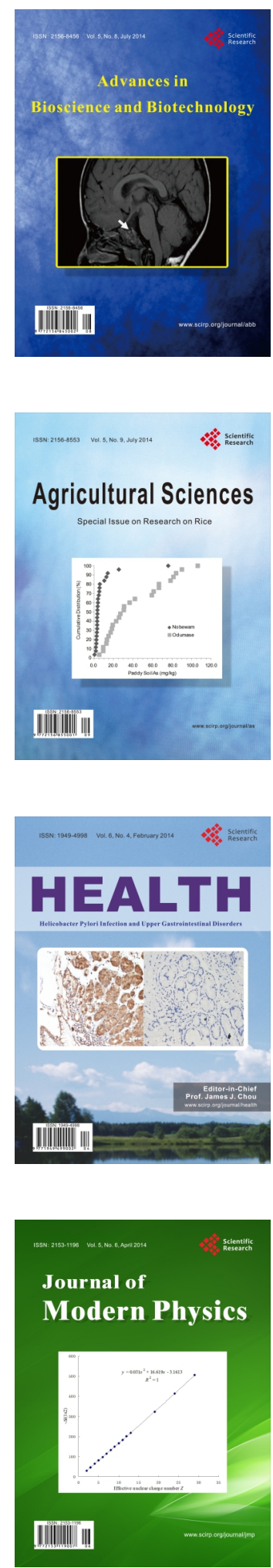
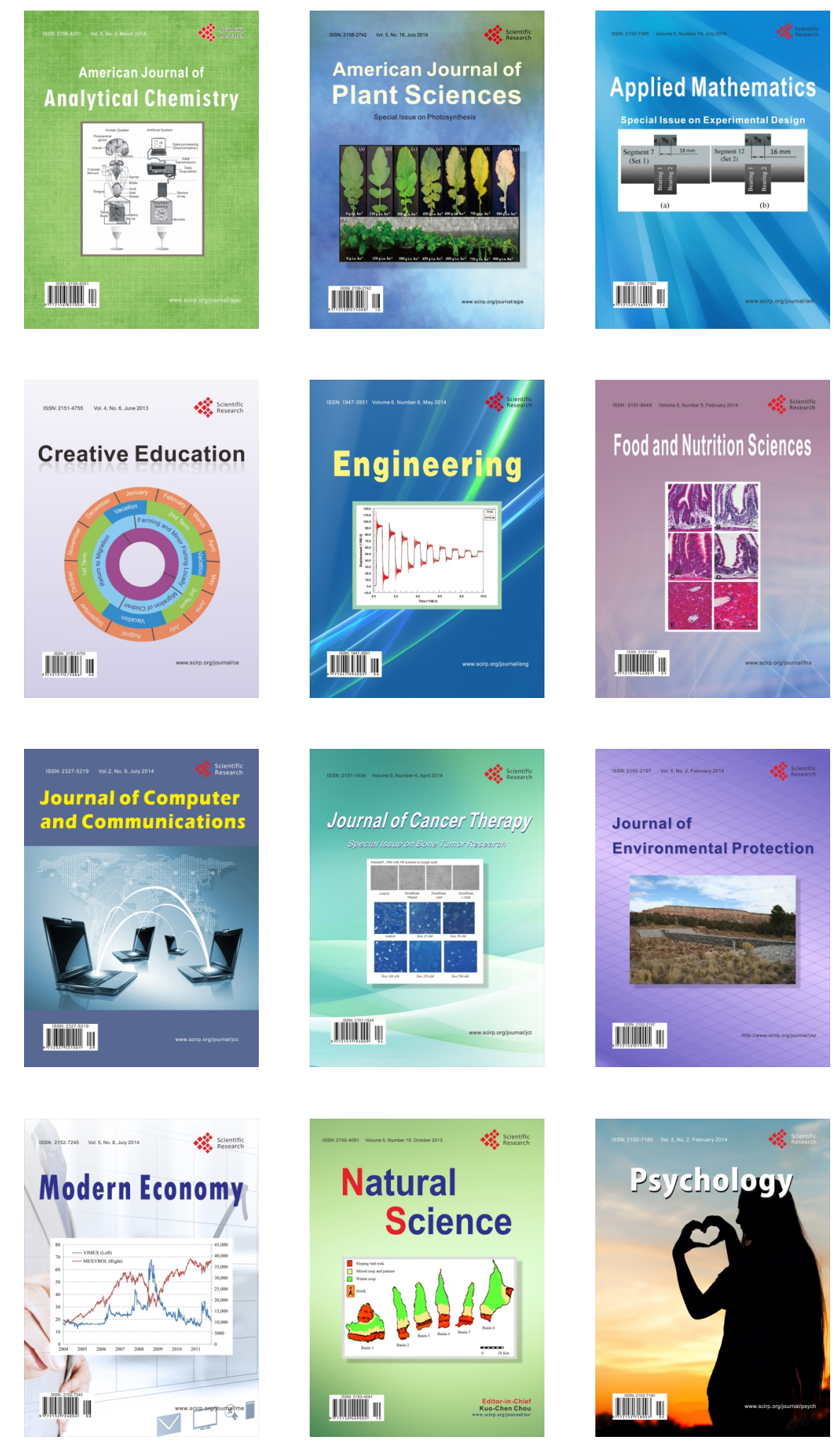